\title{
The Effect of Nutritional Additive of Glycyrrizic Acid, Glabridin and Resveratrol on SARS-coronavirus Replication
}

\author{
Baxodir Muxamadiev ${ }^{1, ~ *}$, Shurangiz Kasimova ${ }^{2}$, Nodirabegim Kasimova ${ }^{3}$ \\ ${ }^{1}$ Department of Chemistry, Bukhara Engineering and Technology Institute, Bukhara, Uzbekistan \\ ${ }^{2}$ Tashkent Pharmaceutical Institute, Tashkent, Uzbekistan \\ ${ }^{3}$ Bukhara State Medical Institute Named After Abu Ali ibn Sino, Bukhara, Uzbekistan
}

Email address:

shurangiz.kasimova@mail.ru (S. Kasimova),nodirabegim.k99@gmail.com (N. Kasimova)

\section{To cite this article:}

Baxodir Muxamadiev, Shurangiz Kasimova, Nodirabegim Kasimova. The Effect of Nutritional Additive of Glycyrrizic Acid, Glabridin and Resveratrol on SARS-coronavirus Replication. International Journal of Biomedical Materials Research. Vol. 9, No. 1, 2021 , pp. 10-12. doi: 10.11648/j.ijbmr.20210901.12

Received: September 1, 2020; Accepted: October 1, 2020; Published: June 22, 2021

\begin{abstract}
The outbreak of SARS requires the search for antiviral compounds to prevent and treat this disease. Currently, there is no specific treatment for coronavirus infection associated with SARS-COVID-19. Among researchers working in this area, there are various approaches to create an effective vaccine against this infection, there is no consensus on this problem. We will assess the antiviral potential of GA, GL, RT against two clinical isolates of coronavirus (M-1 and M-2) from SARS patients admitted to the Bukhara Multifunctional Clinical Center. The chemical structure of these substances interacts with the structures of the virus, changing the various phases of the viral cycle, which is accompanied by irreversible inactivation of viral particles (which are in a free state outside the cells), blocking the introduction of active viral particles through the cell membrane into the cell, as well as disrupting the ability of viruses to synthesize new structural components. Inhibits viruses at concentrations that are non-toxic to normally functioning cells. All these properties of these substances have attracted our attention, and some of them have confirmed their importance. Our results indicate that GA and RT should be used to treat coronavirus infection. RT, in turn, has antiviral, anticancer effects and will also be studied in detail.
\end{abstract}

Keywords: SARS Coronavirus, Glycyrrhizic Acid, Glabridin, Resveratrol, Replication, Enzymes

\section{Introduction}

There is an increasing demand for herbal medicines, nutritional supplements and cosmetics. A review of the chemical nature, namely the structural formula of the studied plant ingredients, shows both general similarities (the presence of phenolic groups) and some differences (not all have a heterocyclic ring, a carboxyl group). Nevertheless, they all have biological activity. For example, GA, GL, RT have antioxidant, antibacterial, antiviral and a number of other activities. These results indicate that research should be carried out more extensively in order to confirm the findings of other authors and to reveal other potential therapeutic effects of these compounds.

The new coronavirus COVID-19 has been identified in patients with severe respiratory syndrome (SARS). SARS is an infectious disease with a high potential for transmission through close contacts. An outbreak of atypical pneumonia in several countries (pandemic) has led to the search for active antiviral compounds (vaccines) to treat this disease. In this work, we evaluated the antiviral activity of GA, GL and RT against two clinical isolates of coronavirus (M-1 and M-2) from SARS patients admitted to a multifunctional clinical center (Bukhara). GA and GL are active components of licorice roots [1,2], and RT is isolated from mulberry leaves [3]. These compounds are used by patients because of their antiviral $[4,5]$, antitumor [6], immunosuppressive [7], etc. $[8]$ activities.

\section{Methods}

On confluent layers of Vero cells, we evaluated the 
cytopathogenicity of the virus evoked 4-5 days after infection. The ratio of the concentration of a compound that reduces cell viability by half $\left(\mathrm{CC}_{50}\right)$ to the concentration of a compound that inhibits cytotoxicity by the same value from the control $\left(\mathrm{EC}_{50}\right)$ gives us a selectivity index. The level of toxicity per cell was determined using a set of MMT-1 cells. (Eurodiagnostics, the Netherlands). In addition, inhibitors of the enzymes inosine monophosphate dehydrogenase ribavirin and mycophenolic acid were used in the study, which did not affect the replication of SARS-associated coronaviruses (SARS-CV). Orotidine monophosphate decarboxylase inhibitors - 6-azauridine and pyrazofurin, suppressed the replication of SARS-CV at non-toxic doses with selectivity indices of 6 and 12, respectively. The selectivity index of GL and RT was 41 and 60, respectively. The most potent inhibitor of SARS-CV replication in Vero cells was GL, which had a selectivity index of 76 (Table 1).

Table 1. Activity of the compounds against SARS associated with coronavirus in Vero cell cultures.

\begin{tabular}{|c|c|c|c|c|}
\hline No. & Compound & $\mathrm{EC}_{50}(\mathrm{mg} / \mathrm{l}) *$ & $\mathrm{CC}_{50}(\mathrm{mg} / \mathrm{l}) *$ & Selectivity index \\
\hline 1. & 6-azauridine & $18-8(2-8)$ & $107(18)$ & 6 \\
\hline 2. & Pyrazofurin & $4-2(0-50)$ & $50(2-6)$ & 14 \\
\hline 3. & Mycophenolic acid & $>60$ & $>60$ & 0 \\
\hline 4. & Ribovirin & $>1100$ & $>1100$ & 0 \\
\hline \multirow[t]{3}{*}{5.} & Glycyrrhizic acid: & & & \\
\hline & a) after adsorption of the virus & $580(70)$ & $>20,000 *$ & $>35$ \\
\hline & b) during and after adsorption of the virus & $280(54)$ & $>20,000$ & $>68$ \\
\hline \multirow[t]{4}{*}{6.} & Glabridin: & & & \\
\hline & a) after adsorption of the virus & $800(82)$ & $>22000$ & $>76$ \\
\hline & b) during and after adsorption of the virus & $500(66)$ & $>18000$ & $>70$ \\
\hline & c) during the adsorption of the virus & $2000(380)$ & $>18000$ & $>12$ \\
\hline \multirow[t]{3}{*}{7.} & Resveratrol: & & & \\
\hline & a) after adsorption of the virus & $900(91)$ & $>16000$ & $>41$ \\
\hline & b) during and after adsorption of the virus & $600(56)$ & $>18000$ & $>64$ \\
\hline
\end{tabular}

$\mathrm{EC}_{50}$ is the effective concentration of the compound required to suppress the cytopathic effect up to $50 \%$ of the control value $\mathrm{CC}_{50}$ is the cytotoxic concentration of the compound that reduces cell viability to $50 \%$, NC-not detected, * SD-average of 10 analyzes ** At the maximum concentration used $(20 *$ $\left.10^{3} \mathrm{mg} / \mathrm{l}\right)$ there was a decrease in cell viability by $20-30 \%$.

In addition to inhibiting viral replication, GA inhibits the adsorption and penetration of the virus into the host cell (Vero cells) - the first stages of the replicative cycle, GA was less effective when administered during the adsorption period than when added after virus adsorption $\left(\mathrm{EC}_{50} 580 \mathrm{mg} / \mathrm{L}\right.$ versus $2300 \mathrm{mg} / \mathrm{L}$, respectively) [9]. GA was most effective when added both during growth and after an adsorption period $\left(\mathrm{EC}_{50} 280 \mathrm{mg} / \mathrm{L}\right)$.

The effect of GA on SARS-CV replication in Vero cells has been shown. We have detected replication of SARS-CV with serum samples from SARS patients. The manifestation of antigens (viral) was much lower in the cultures treated with $1000 \mathrm{mg} / \mathrm{l} \mathrm{GA}$ than in any other culture; high concentrations of GA (400 mg / 1) completely suppressed viral replication. (Unpublished data from authors).

\section{Results}

When comparing the antiviral activity of 6-azauridine, ribovirin, GA against several pathogenic flavoviruses, it was found [6] that ribovirin and 6-azauridine were active, but not selective inhibitors when assessing them in relation to cell growth inhibition. GA had a low selectivity index, but was a significantly potent inhibitor of replication of all viruses tested. These authors report that the $\mathrm{EC}_{50}$ for GA was 316$625 \mathrm{mg} / \mathrm{L}$ (added twice during an incubation period of 7 days). Considering that compounds were added twice during the entire incubation period, the $\mathrm{EC}_{50}$ for $\mathrm{GA}$ that we found
(Table 1) indicates a higher sensitivity of SARS-CV to this drug than that found by Grance (6) and Toch (5) and Colleagues. The mechanism of GA activity against SARS is still unclear [10]. GA influences cellular signaling pathways such as protein kinase $\mathrm{C}$, casein kinase II and transcription factors such as activator protein 1 and nuclear factor $\mathrm{kB}$ [5]. In addition, GA and its metabolite aglycone $18 \beta$-glycerritic acid enhance the expression of inducible nitrous oxide synthase $\left(\mathrm{N}_{2} \mathrm{O}\right)$ and nitrous oxide production in macrophages. $\mathrm{N}_{2} \mathrm{O}$ inhibits the replication of several viruses, such as Japanese encephalitis virus (a member of the Flaviviridae family), which can also inhibit GA.

Preliminary results of our experiments show that GA induces $\mathrm{N}_{2} \mathrm{O}$ synthase in Vero cells and that viral replication is inhibited by the addition of a nitrous oxide donor (DETA NONO) to the culture medium.

GA has previously been used to treat patients with HIV1 and chronic hepatitis $C$ virus [14]. The resulting low P24 antigen concentrations in $\mathrm{HIV}-1$ patients who were given this compound have been associated with upregulation of chemokines [11]. Rare side effects such as increased blood pressure and hypokalemia have been reported in some patients after several months of glycyrrhizin treatment [13]. SARS treatment is necessary only for a short time. Since the side effects of this compound are known and can be controlled, proper monitoring can lead to the effective use of GA as a drug for the treatment of SARS. It is reported $(5,6)$ that ribovirin has a number of toxic effects 
when administered to patients with SARS, including hemolysis (76\% of patients) and a sharp decrease in hemoglobin ( $49 \%$ of patients). However, although high doses of GA were used in clinical trials, this compound had few toxic effects compared to other treatment regimens, and the drug was reported to be clinically effective [15].

\section{Conclusion}

The studied compounds, in relation to the replication of the SARS-CV virus, require further analysis based on their structure, the reactivity of their functional groups in relation to oxidants, as well as their biochemical parameters (action, first of all, on the active centers of enzymes, then on the membranes (proteinaceous) [12].

The future search for compounds (preferably of natural origin) of therapeutic interest against SARS-CoV will be greatly facilitated by establishing the growth of SARS-CoV in human cells.

The study of the interelation between the chemical nature and their biological, primarily antiviral activity is quite promising and serves as the goal of further research by the authors.

\section{References}

[1] Mukhamadiyev B. T. et al. «The kinetics of supercritical $\mathrm{CO}_{2}$ - extraction glycyrrhizic acid from licorice roots». Butlerov communications V. 48, 2016, NII, 35-41.

[2] Mukhamadiyev B. T. et al. «Production of extracts from vegetable raw materials by carbon dioxide» Food science and Technology, V. 14, №1, 2020, 54-64.

[3] Mukhamadiyev B. T. et al. «Supercritical $\mathrm{CO}_{2}$ - extraction resveratrol's from mulberry leaves». Butlerov communications V. 49, 2017, NI, 119-116.

[4] Cunate J. et al. «Glycirrhizin, an active component of licorice roots and replication of SARS-associated coronavirus». The LANCET, V. 361, 14, 2003. P. 2045.
[5] Tioen M. et al. «Extraction of Glycyprhizic acid and Glabridin from Licorice», S. Sut. Mol. Sci, 9, 2008, 571.

[6] Grance I. M. et al. «Interferon, ribavirin, 6-azauridine and glycyrrhizine: antiviral compounds active against pathogenic flavoviruses». Antiviral Res. 2013, 98, 82.

[7] Baltina L. et al. «Prospects for the creation of new antivir.al drug based on glycrrhizic acid and its derivatives: a review». Pharmaceutical chemistry I. 43, 2009, 3-12.

[8] Haraguchi $\mathrm{H}$ et al. «Antioxidative and superoxide scavenging activities of retrochalcones in Glycyrrhiza inflata», Bioorganic and Medicinal Chemistry, 16 (2008), 109-117.

[9] Fan YG, Shi ZQ., He BL. Extraction, separation \& application fot Glycyrrhizinic acid. Natural Product Research \& Development; 1996, 8: 93-99.

[10] Jatav VS., Singh SK., Sharma AK. Recent Pharmacological trends in Glycyrrhiza glabra. International Journal of Pharmaceutics \& Pharmaceutical Frontier Research; 2011, 1: $170-85$.

[11] Lakshmi T., Geetha RV., Glycyrrhiza glabra commonly known as licorice-a therapeutic review. International Journal of Pharmaceutics \& Pharmaceutical Sciences, 2011, 3: 20-25.

[12] Mirmala P., Selvaraj T. Anti-inflammatory \& antibacterial activities of Glycyrrhiza glabra. Journal of Agriculture Technology: 2011, 7: 815-23.

[13] Yazdi A., Sardari S., Sayyah Md. Evaluation of anticonvulsant activity of leaves of Glycyrrhiza glabra grown in Iran as a possible renewable source for anticonvulsant compounds. Iranian journal of Pharmaceutical research. 2011, 6: 18-27.

[14] Latif M., Iqbal L., Fatima N. evaluation of antioxidant \& urease inhibition activity of roots of Glycyrrhiza glabra. Pakistan journal of Pharmaceutical Sciences; 2012, 25: 99102.

[15] Nitalikar M., Munde KC, Dhore BV. Studies of antibacterial activities of Glycyrrhiza glabra root extract. International Journal of Pharmaceutics \& Pharmaceutical Sciences, 2010, 2: 899-901. 